\title{
Synthetic route to soluble sulfonated poly(arylene sulfone imide)
}

\author{
Eiichi Shoji and Nanase Nasuno
}

A synthetic route to high-molecular-weight sulfonated poly(arylene sulfone imide), which cannot be prepared via the direct synthesis of a polyimide moiety due to the presence of electron-deficient groups in the monomers, has been developed. A target polymer was synthesized by the oxidation of a poly(arylene sulfide imide), which was readily synthesized by the conventional synthetic route for polyimides. Notably, because of good solubility of the sulfonyl moieties, the obtained polymer was also highly soluble, and thus it was possible to fabricate a solution-cast polymer film. Therefore, sulfonated poly(arylene sulfone imide)s are potentially soluble sulfonated poly(arylene imide)s for applications where solvent solubility is an issue.

Polymer Journal (2014) 46, 694-698; doi:10.1038/pj.2014.61; published online 30 July 2014

\section{INTRODUCTION}

Aromatic polyelectrolytes have received significant attention because of their thermal stability, mechanical strength, flexibility and chemical stability. ${ }^{1}$ In fact, unlike conventional polyelectrolytes based on poly(alkylene sulfonate)s, ${ }^{1,2}$ polyelectrolytes consisting of sulfonated aromatic engineering plastics have been evaluated as membranes for fuel cell batteries and high-performance polymer actuators. ${ }^{1,3-6}$ Poly(perfluoroalkylene) sulfonic acids, that is, Nafion or Flemion, are commercially available polyelectrolytes that have been examined for such applications, and their electrochemistry has been extensively investigated. ${ }^{7,8}$ However, these polymers suffer from solvent swelling/ solubility and thermal instability. For example, these polymers are highly swollen or soluble in common alkyl alcohols and alkyl ketones. Therefore, high-performance polyelectrolytes that contain aromatic backbones are considered to be alternatives to perfluorocarbon sulfonates with improved chemical resistance and thermal stability. ${ }^{1,2}$ In this context, we have focused on the development of polyelectrolytes based on aromatic polyimides with excellent performance properties for energy-related applications such as polymer actuators. ${ }^{9-12}$ For many advanced applications, it is very important to design polyimide structures that have good solvent solubility, are non-hydrolyzable and can be applied as cast films. Some of the merits of the polyimide backbone include its ease of polymerization and the commercial availability of various aromatic diamine and acid anhydride monomers. ${ }^{13-16}$ In general, polyimides composed of five-membered rings are known to have better chemical properties such as good solvent resistance, mechanical and dimensional stability, and radiation stability. ${ }^{13-16}$ Although they are designed to have good chemical properties given their structural similarity to engineering plastics, most polyimides are insoluble in very polar organic solvents such as dimethyl sulfoxide and dimethylformamide. As a result, it is not possible to fabricate solution-processed films of these polymers. In addition, the hydrolyzable imide five-membered ring is problematic because it leads to reduced moisture and thermal stability for the polymers. It should, however, be possible to overcome these drawbacks by modifying the structure of the imide moiety. It is known that six-membered imide rings are more resistant to hydrolysis via the nucleophilic attack of water than five-membered rings due to reduced ring strain. ${ }^{17-20}$ In addition, six-membered rings can be readily produced thermodynamically from naphthalene derivatives. Increased chemical stability is also achieved because of the resonance structures of naphthalene. ${ }^{17-20}$ On the other hand, to increase the solvent solubility of aromatic polyimides, the introduction of more polar substituent groups that can be strongly solvated is very effective. ${ }^{21}$ Several strategies are possible for increasing the solvent solubility of these polymers. ${ }^{21-26}$ For example, it should be noted that the solvent solubility of polymers that contain sulfur atoms can be easily manipulated by choosing thioether, sulfoxide, sulfonyl or sulfonate moieties. ${ }^{21-26}$ In other words, the solvent solubility of sulfur-containing polymers can be manipulated by switching the oxidation state of the sulfur atoms. For example, poly(arylene ether thioether)s can be converted to sulfonyl polymers by the simple oxidation of sulfur atoms, and the obtained poly(arylene ether sulfone)s are known as engineering plastics with good chemical and thermal stability. ${ }^{21}$ This method for increasing the solvent solubility of polymer structures is quite important because of the feasibility of the chemical reaction (that is, simple conversion of the oxidation state of the sulfur atoms). Herein, we report an easy and simple method for preparing poly(arylene imide sulfonate)s that have good solvent solubility by the manipulation of the chemical structures of polymers containing sulfur atoms. 


\section{EXPERIMENTAL PROCEDURE}

\section{Materials}

1,4,5,8-Naphthalenetetracarboxylic acid anhydride (NCA), 4,4'-diaminodiphenyl ether, 4,4'-diaminodiphenyl sulfide and 4,4'-diaminodiphenyl sulfone (ASO) were purchased from Tokyo Kasei (Tokyo, Japan) and were purified by vacuum sublimation. Triethylamine (TEA), benzoic acid, sulfuric acid and hydrogen peroxide $(30 \%)$ were purchased from Wako Pure Chemical Industries (Osaka, Japan) and used as received. Purified water (18 Mega $\mathrm{Ohm}$ ) obtained from a Millipore purification system was used for all the experiments unless otherwise noted. The monomer 4,4'-diaminodiphenyl ether-2,2'-disulfonic acid (AES) was synthesized by the sulfonation of $4,4^{\prime}$ diaminodiphenyl ether. ${ }^{27}$

\section{Characterization methods}

${ }^{1} \mathrm{H}$ and ${ }^{13} \mathrm{C}$ NMR spectra were recorded on a JEOL JNM-ECP600 $600 \mathrm{MHz}$ spectrometer (JEOL, Tokyo, Japan) using DMSO-d6 as solvent. Gel permeation chromatography analyses were run at $40^{\circ} \mathrm{C}$ in dimethylformamide containing $10 \mathrm{mM} \mathrm{LiBr}$ (a flow rate of $1.0 \mathrm{ml} \mathrm{min}^{-1}$ ) on a TOSOH DP-8020 pump, SD-8020 degasser, CO-8020 column oven, with a series of columns (TSK-GEL a-3000 and a-M, Tosoh, Tokyo, Japan) using a TOSOH RI-8020 RIdetector. X-ray photoelectron spectroscopy (XPS) spectra of C1s, N1s, O1s and S2p3/2 were recorded on a JEOL JPS-9010MC spectrometer.

\section{Synthesis of poly(arylene sulfide imide)}

To a 100-ml three-necked round-bottom flask equipped with a mechanical stirring unit, AES $(0.432 \mathrm{~g}, 1.2 \mathrm{mmol}), \mathrm{m}$-cresol $(10 \mathrm{ml})$ and TEA $(0.291 \mathrm{~g})$ were charged under nitrogen gas. After AES was completely dissolved, NCA $(1.609 \mathrm{~g}, 6.0 \mathrm{mmol})), 4,4^{\prime}$-diaminodiphenyl sulfide $(1.038 \mathrm{~g}, 4.8 \mathrm{mmol})$ and benzoic acid $(1.026 \mathrm{~g})$ were added. The mixture was mechanically stirred at room temperature for $10 \mathrm{~min}$ and then heated at $80^{\circ} \mathrm{C}$ for $5 \mathrm{~h}$ and then $180^{\circ} \mathrm{C}$ for $20 \mathrm{~h}$. The reaction mixture was subsequently cooled to $100^{\circ} \mathrm{C}$, additional $\mathrm{m}$-cresol $(20 \mathrm{ml})$ was added to dilute the highly viscous solution, and then the solution was poured into acetone. A fiber-like precipitate was filtered, thoroughly washed with acetone using a Soxhlet extractor, and then dried in vacuo at $50{ }^{\circ} \mathrm{C}$ for $20 \mathrm{~h}$. The yield of the polymer was $94 \%$. FT-IR (ATR-ZnSe, $\mathrm{cm}^{-1}$ ): 1711.5, 1667.2, 1578.5, 1341.3, 1244.8, 1193.7, 1079.9, 1017.3, 981.6. XPS(BE, eV) C1s: 285.6, 289.0, N1s: 402.0, O1s: 532.1, S2p3/2: $170.3,169.0$

Oxidative conversion to poly(arylene sulfone imide)

To a 100-ml round-bottom flask equipped with a magnetic stirring unit, poly(arylene sulfide imide) $(0.8 \mathrm{~g})$, acetic acid $(120 \mathrm{ml})$, sulfuric acid $(97 \%$, $10 \mathrm{ml})$ and hydrogen peroxide $(30 \%, 10 \mathrm{ml})$ were charged, and the mixture was stirred at room temperature for $40 \mathrm{~h}$. The precipitate was then filtered, thoroughly washed with methanol using a Soxhlet extractor, and then dried in vacuo at $50{ }^{\circ} \mathrm{C}$ for $20 \mathrm{~h}$. The yield of the polymer was $98 \% .{ }^{1} \mathrm{H}$ NMR(DMSO- $\left.\mathrm{d}_{6}, \delta\right): 8.73,8.30,8.05,7.85,7.46,7.23 .{ }^{13} \mathrm{C}$ NMR(DMSO-d $\mathrm{d}_{6}$, $\delta), \delta: 163.3,141.4,131.4,131.1,129.1,127.5,127.3$. FT-IR(ATR-ZnSe, $\left.\mathrm{cm}^{-1}\right)$ : 1714.4, 1671.0, 1578.5, 1446.4, 1340.3, 1243.9, 1155.2, 1016.3, 981.6. XPS(BE, eV) C1s: 285.6, 289.0, N1s: 402.0, O1s: 531.5, 532.6, S2p3/2: 167.5, 169.5.

\section{Direct synthesis of poly(arylene sulfone imide)}

To a 100-ml three-neck round-bottom flask equipped with a mechanical stirring unit, AES $(0.432 \mathrm{~g}, 1.2 \mathrm{mmol}), \mathrm{m}$-cresol $(10 \mathrm{ml})$ and TEA $(0.291 \mathrm{~g})$ were charged under nitrogen gas. After AES was completely dissolved, NCA $(1.609 \mathrm{~g}, 6.0 \mathrm{mmol})$, ASO $(1.192 \mathrm{~g}, 4.8 \mathrm{mmol})$ and benzoic acid $(1.026 \mathrm{~g})$ were added, and the mixture was mechanically stirred at room temperature for $10 \mathrm{~min}$ and then heated at $80^{\circ} \mathrm{C}$ for $5 \mathrm{~h}$ and then $180^{\circ} \mathrm{C}$ for $40 \mathrm{~h}$. The reaction mixture was subsequently cooled to $100^{\circ} \mathrm{C}$, additional m-cresol $(20 \mathrm{ml})$ was added to dilute the highly viscous solution, and then the solution was poured into acetone. A powder-like precipitate was filtered, thoroughly washed with acetone using a Soxhlet extractor, and then dried in vacuo at $50^{\circ} \mathrm{C}$ for $20 \mathrm{~h}$. The yield of the polymer was $89 \% .{ }^{1} \mathrm{H}$ NMR(DMSO- $\left.\mathrm{d}_{6}, \delta\right): 8.73,8.29,7.91$, 7.85, 7.41, 7.26. ${ }^{13} \mathrm{C}$ NMR(DMSO-d 6 , $\delta$ ): $163.3,141.4,141.2,131.5,131.0$, $129.1,127.5,127.3$.

\section{RESULTS AND DISCUSSION}

\section{Monomer synthesis}

The polymer AES was synthesized by the sulfonation of $4,4^{\prime}$ diaminodiphenyl ether using fuming sulfuric acid. During this reaction, the amino groups of $4,4^{\prime}$-diaminodiphenyl ether are protonated under acidic conditions. Because the protonated amino groups are strong electron-withdrawing groups, sulfonation mainly occurs at a position meta to these groups. In addition, the electron density is increased at the ortho position, further promoting electrophilic substitution at this site, which also corresponds to the position meta to the protonated amino groups. As a result, AES was obtained in good yield $(90 \%)$.

\section{Synthetic strategy for polymer synthesis}

It is known that the polycondensation of aromatic diamines bearing electron-withdrawing groups at the para position with acid anhydrides is inhibited because of the poor electron density of the diamines. Thus, as shown in Figure 1, our strategy involved
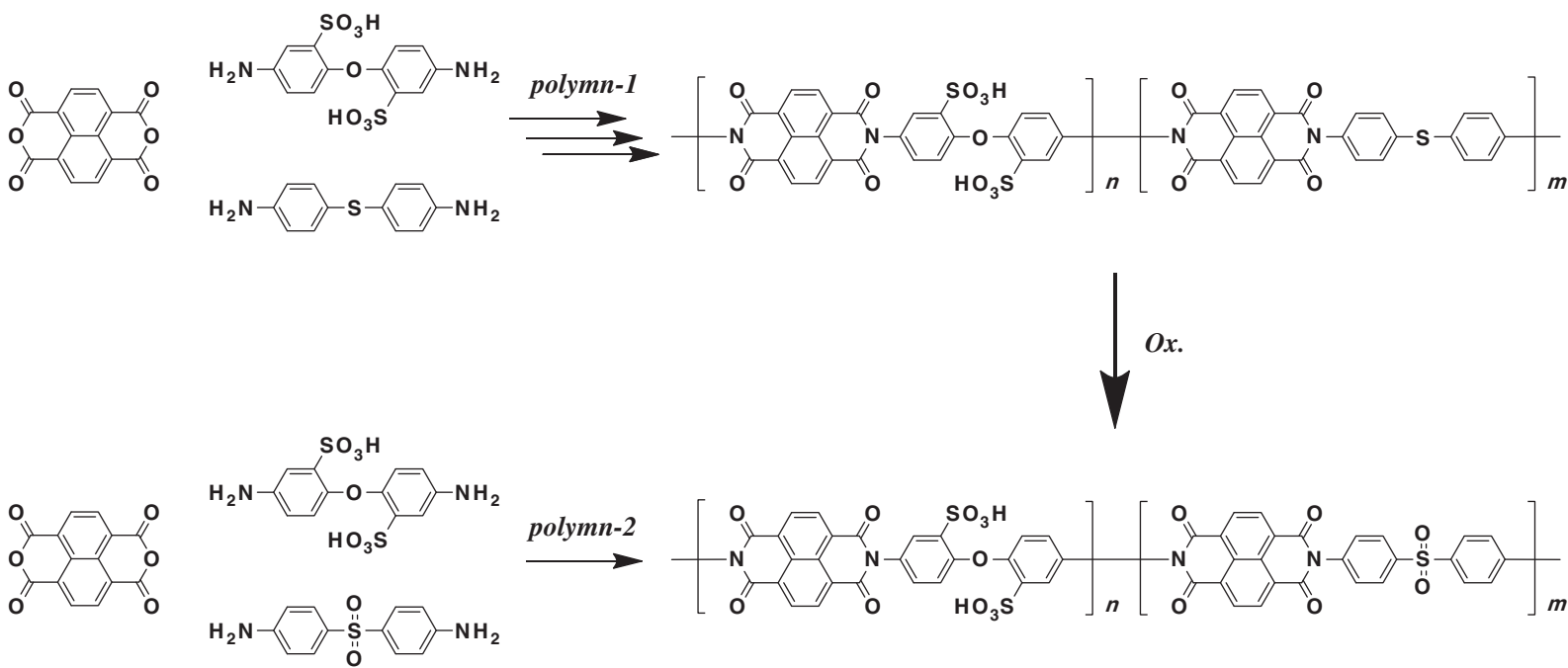

Figure 1 Synthetic route (polymn-1) to poly(arylene sulfone imide)s by the oxidation of the sulfur atoms in poly(arylene sulfide imide)s. 
the synthesis of poly(arylene sulfone imide)s by the oxidation of the sulfur atoms in poly(arylene sulfide imide)s (see polymn-1 of Figure 1). This approach avoids the inactivity of ASO with respect to polymerization. Poly(arylene sulfide imide)s can be readily synthesized by the polycondensation of aromatic diamines bearing electron-donating sulfur substituents at the para position. The oxidation of poly(arylene sulfide imide)s (Figure 1) should be simple and clean in general. Therefore, this oxidation route, specifically using hydrogen peroxide in the presence of a strong acid such as sulfuric acid, was selected.

\section{Polymer synthesis}

We focused on the polyelectrolyetes that could be an alternative to Nafion. The ratio 4:1 produces EW (equivalent weight) of $\sim 1000$, and this value is close to EW:1100 of Nafion. Thus, we focused on the

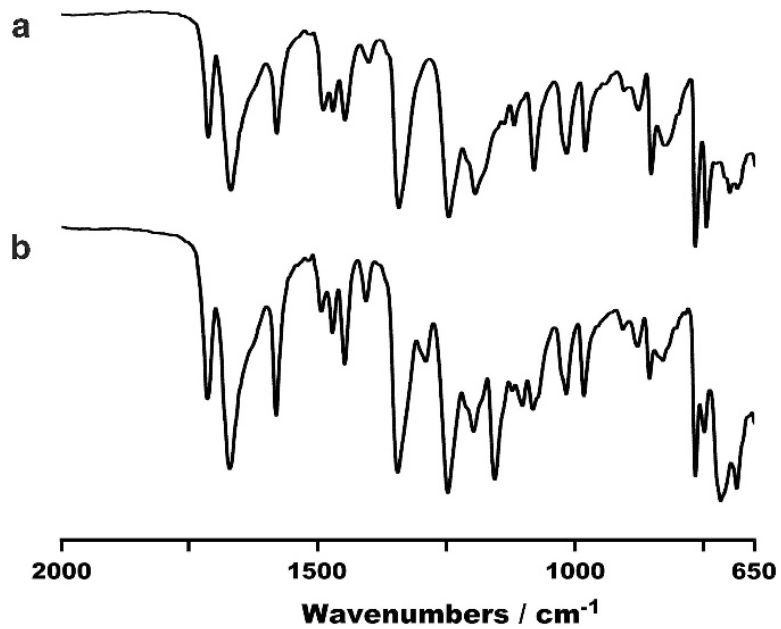

Figure 2 Fourier-transform infrared spectra before and after the oxidation of the poly(arylene sulfone imide). Spectrum (a) corresponds to the chemical structure of the poly(arylene sulfide imide), while spectrum (b) corresponds to that of the poly(arylene sulfone imide). polycondensation ratio of 4:1. To obtain poly(arylene sulfide imide), the polycondensation of NCA, AES and 4,4'-diaminodiphenyl sulfide was conducted in $m$-cresol (see polymn- 1 of Figure 1). TEA was used to capture the protons released from the protonated amino groups during polymerization, while benzoic acid was used as the catalyst for polymerization. After the completion of polycondensation, a fiber-like precipitate was obtained following reprecipitation in acetone. The appearance of the precipitate suggested that the polymer had a highmolecular weight, and measured $M_{\mathrm{w}}$ was 335400 . This result also supported the assumption that aromatic diamines bearing electrondonating groups at the para position promote polycondensation with acid anhydrides.

The corresponding poly(arylene sulfone imide) was then obtained by the oxidation of poly(arylene sulfide imide), as shown in Figure 1. The sulfide groups in the poly(arylene sulfide imide) were converted to sulfonyl groups using hydrogen peroxide in acetic acid. The addition of concentrated sulfuric acid promoted oxidation, such as sulfonation of the aromatic rings and/or cleavage of the imide ring, and hence, the reaction was conducted in acetic acid. For comparison, the poly(arylene sulfone imide) was also directly synthesized by the polymerization of NCA, AES and ASO in $m$-cresol (see polymn- 2 of Figure 1). TEA and benzoic acid were added to promote polymerization. The powder-like precipitate that was obtained after reprecipitation in acetone suggested that the polymer had a low-molecular weight. This result confirms the assumption that aromatic diamines bearing electron-withdrawing sulfone groups at the para position have decreased reactivity with respect to polycondensation with acid anhydrides. The direct synthesis of poly(arylene sulfone imide)s, which contain both electron-deficient sulfone and sulfonate groups, was not smooth, because the viscosity of reaction mixture during the polymerization was not effectively high. The required starting monomers have very low electron densities on the amino groups. In fact, the direct polycondensation of the target poly(arylene sulfone imide) using ASO afforded a powder product, the $M_{\mathrm{w}}$ of the polymer was 37100 . The film cast from a dimethyl sulfoxide solution of this polymer was brittle. In contrast, the film obtained from the solutioncasting of the poly(arylene sulfone imide) polymer prepared via the oxidation of the corresponding poly(arylene sulfide imide) was

Table 1 Solvent solubilities of sulfonated polyimides in polar organic solvents

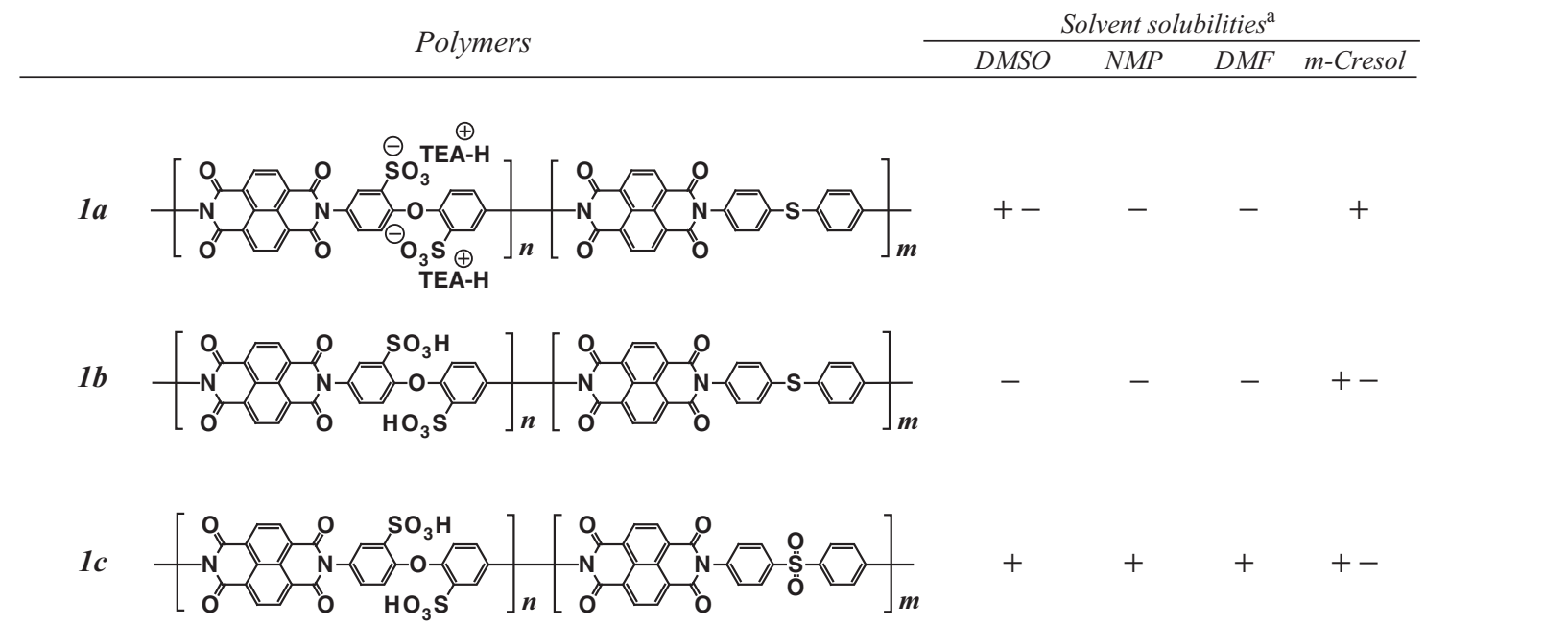

Abbreviations: DMSO, dimethyl sulfoxide; DMF, dimethylformamide; NMP, $\mathrm{N}$-methylpyrrolidone.

a + : soluble, \pm : partially soluble, - : insoluble. 


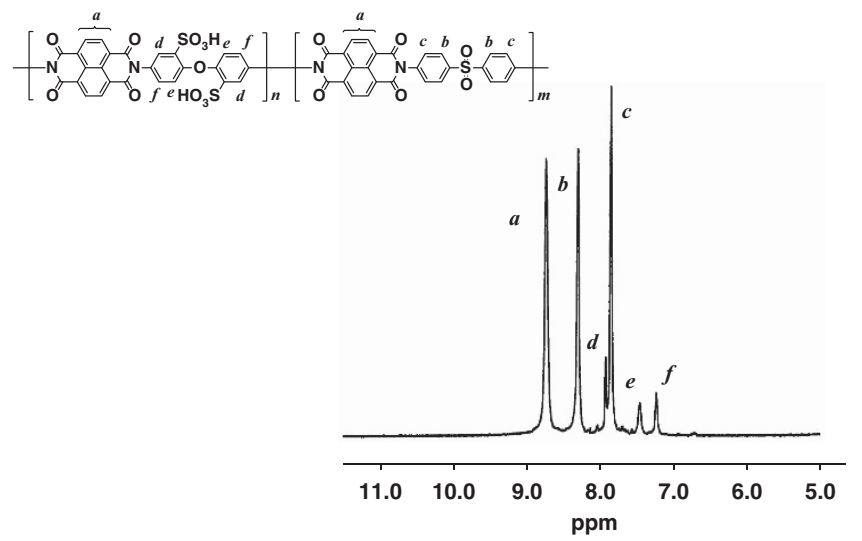

Figure $3{ }^{1} \mathrm{H}$-NMR spectrum of the polymer obtained after the oxidation of poly(arylene sulfone imide). The spectrum corresponds to the chemical structure of the poly(arylene sulfone imide).

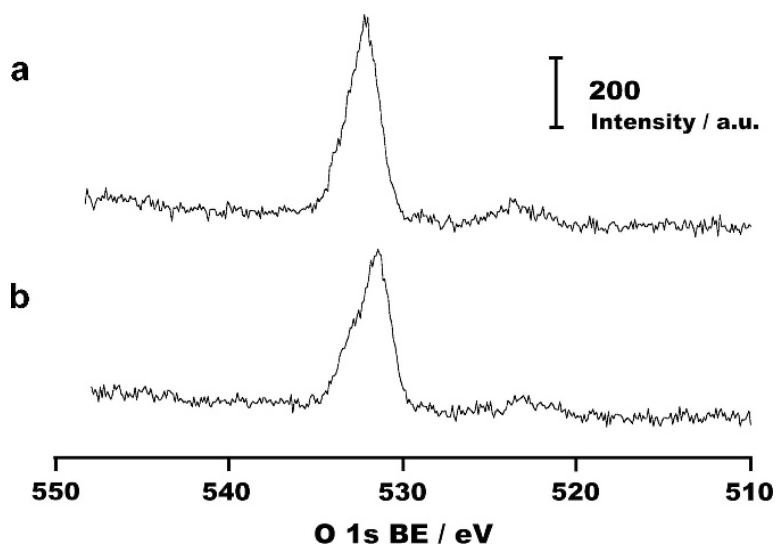

Figure 4 01s X-ray photoelectron spectroscopy spectra of the polymer (a) before and (b) after the oxidation of the poly(arylene sulfone imide).

flexible. Figure 2 shows the infrared spectroscopy spectra of the two polymers before (a) and after (b) the oxidation of the poly(arylene sulfide imide). In both Figures $2 \mathrm{a}$ and $\mathrm{b}$, the strong absorption bands near 1712 and $1667 \mathrm{~cm}^{-1}$ are assigned to the stretching vibrations of the carbonyl groups of the imide rings, indicating that imide rings are present in both polymers. These imide rings are considered to be sixmembered rings that are bonded to naphthalene rings. In Figure $2 b$, the broad peak near $1245 \mathrm{~cm}^{-1}$ and the peak near $1080 \mathrm{~cm}^{-1}$ correspond to stretching vibrations of sulfonic acid groups. The spectrum in Figure 2b also contains peaks near 1155 and $1292 \mathrm{~cm}^{-1}$, attributable correspond to the stretching vibrations of sulfonyl groups. These results indicate that the oxidized polymer contains sulfonyl groups. To further confirm the structural assignments, ${ }^{1} \mathrm{H}-\mathrm{NMR}$ analysis of the polymers before and after oxidation was then attempted. As is shown in Table 1 , the two polymers $1 \mathrm{~b}$ and $1 \mathrm{c}$ had different solubilities in dimethyl sulfoxide.

Therefore, because of the poor solvent solubility of the poly(arylene sulfide imide) (1a and $1 \mathrm{~b}$ ), it was not possible to obtain its ${ }^{1} \mathrm{H}-\mathrm{NMR}$ spectrum. Thus, only the spectrum of the poly(arylene sulfone imide) (1c) is shown in Figure 3. Given the copolymerization ratio of 1:4 for the AES: 4,4'-diaminodiphenyl sulfide monomers, the integral ratio of $a: b=5: 4$ in the spectrum was reasonable, and the synthesis of the poly(arylene sulfone imide) (b) was confirmed. It should be noted that the increased solvent solubility of the poly(arylene sulfone imide) compared to that of the poly(arylene sulfide imide) can be attributed to the higher dipole moment of the sulfone group; the dipole moment of diphenyl sulfide is $1.46 \mathrm{D}$, whereas that of diphenyl sulfone is $5.07 \mathrm{D}$.

XPS was then used to gain further information on the structures of the polymers; XPS spectra of the C1s, N1s, O1s and S2p3/2 of the poly(arylene sulfide imide) and poly(arylene sulfone imide) were evaluated (see Supplementary Data). No differences were detected in the C1s spectra, indicating that the aromatic imide and other aromatic rings were not cleaved during oxidation. The N1s spectra of the two polymers were also similar, with each containing a peak at $\sim 402 \mathrm{eV}$, further supporting this conclusion. However, as can be seen in Figure 4, the O1s spectra were different for the two polymers. The peak at $532.1 \mathrm{eV}$, which appears in both spectra, corresponds to the oxygen atoms of the imide rings. The new peak at $531.5 \mathrm{eV}$ in the spectrum of the poly(arylene sulfone imide) corresponds to the oxygen atom of the sulfonyl group. In addition, the peak at $170 \mathrm{eV}$ in the S2p3/2 spectrum of the poly(arylene sulfide imide), which corresponds to the sulfur atoms of the sulfide groups, shifted to $\sim 167.5 \mathrm{eV}$ in the $\mathrm{S} 2 \mathrm{p} 3 / 2$ spectrum of the poly(arylene sulfone imide), which corresponds to the sulfur atoms in the sulfonyl groups.

\section{CONCLUSIONS}

A simple synthetic route to poly(arylene sulfone imide) from poly(arylene sulfide imide) was confirmed. In contrast to poly(arylene sulfone imide) obtained via direct synthesis, a film obtained from solution-casting of a poly(arylene sulfone imide) polymer prepared via the oxidation of the corresponding poly(arylene sulfide imide) was mechanically tough and more flexible. In addition, as shown in Table 1, the poly(arylene sulfone imide) exhibited dramatically increased solvent solubility compared to that of the poly(arylene sulfide imide), which was only soluble in $m$-cresol. Because $m$-cresol is highly toxic, it is not practical for use in industrial-scale film casting processes. The introduction of the sulfone group in the insoluble poly(aromatic imide) increased the solvent solubility dramatically. Therefore, the preparation of polysulfides followed by oxidation will be a worthwhile synthetic strategy for improving the solubility of this important class of polymers.

\section{ACKNOWLEDGEMENTS}

This study was partially supported by a Grant-in-Aid for Scientific Research from the JSPS (KAKENHI grant number 21550205). This work was also partially supported by research grants from the University of Fukui.

1 Hickner, M. A., Ghassemi, H., Kim, Y. S., Einsla, B. R. \& McGrath, J. E. Alternative polymer systems for proton exchange membranes (PEMs). Chem. Rev. 104, 4587-4611 (2004).

2 Savadogo, 0. Emerging membranes for electrochemical systems-Part II. High temperature composite membranes for polymer electrolyte fuel cell (PEFC) applications. J. Power Sources 127, 135-161 (2004).

3 Wang, F., Hickner, M., Kim, Y. S., Zawodzinski, T. A. \& McGrath, J. E. Direct polymerization of sulfonated poly(arylene ether sulfone) random (statistical) copolymers: candidates for new proton exchange membranes. J. Memb. Sci. 197, 231-242 (2002)

4 Ghassemi, H., Ndip, G. \& McGrath, J. E. New multiblock copolymers of sulfonated poly(4'-phenyl-2,5-benzophenone) and poly(arylene ether sulfone) for proton exchange membranes. II. Polymer (Guildf) 45, 5855-5862 (2004).

5 Zhang, Y., Litt, M., Savinell, R. F. \& Wainright, J. S. Polym Prepr. Am. Chem. Soc. Div. Polym. Chem. 40, 480 (1999).

6 Guo, X., Fang, J., Watari, T., Tanaka, K., Kita, H. \& Okamoto, K.-i. Novel sulfonated polyimides as polyelectrolytes for fuel cell application. 2. synthesis and proton conductivity of polyimides from 9,9-bis(4-aminophenyl)fluorene-2,7-disulfonic acid. 2002 35, 6707-6713 (2002). 
7 Shu, C. F. \& Anson, F. C. Dynamic consequences of ionic permselectivity-rapid ejection from nafion coatings of anions generated electrochemically from cationic precursors. J. Am. Chem. Soc. 112, 9227-9232 (1990).

8 Szentirmay, M. N. \& Martin, C. R. Ion-exchange selectivity of Nafion films on electrode surfaces. Anal. Chem. 56, 1898-1902 (1984).

9 Shoji, E. \& Hirayama, D. The effects of the potential and polarization time on the performance of ionic polymer metal composite actuators: a control of forward and reverse displacements. Polym. Adv. Technol. 18, 346-352 (2007).

10 Shoji, E. \& Hirayama, D. Effects of humidity on the performance of ionic polymer-metal composite actuators: experimental study of the back-relaxation of actuators. J. Phys. Chem. B 111, 11915-11920 (2007).

11 Shoji, E., Takagi, S. \& Araie, H. A novel conducting fabric polymer composites as stretchable electrodes: one step fabrication of chemical actuators. Polym. Adv. Technol. 20, 423-426 (2009).

12 Shoji, E. \& Komoda, Y. Pulse width modulation (PWM) control of the bending displacement and force generation of ionomer-based polymer actuators. Polym. Adv. Technol. 24, 752-757 (2013).

13 Wieneke, J. U. \& Staudt, C. Thermal stability of 6FDA-(co-)polyimides containing carboxylic acid groups. Polym. Degrad. Stabil. 95, 684-693 (2010).

14 Kulkarni, M., Kothawade, S., Arabale, G., Wagh, D., Vijayamohanan, K., Kulkarni, R. A. \& Vernekar, S. P. Synthesis and characterization of polyimides and co-polyimides having pendant benzoic acid moiety. Polymer (Guildf) 46, 3669-3676 (2005).

15 Jang, W., Lee, C., Sundar, S., Shul, Y. G. \& Han, H. Thermal and hydrolytic stability of sulfonated polyimide membranes with varying chemical structure. Polym. Degrad. Stabil. 90, 431-440 (2005)

$16 \mathrm{Hsu}$, S. L.-C. \& Fan, M. H. Synthesis and characterization of novel negative-working aqueous base developable photosensitive polyimide precursors. Polymer (Guildf) 45, 1101-1109 (2004).

17 Sun, F., Wang, T., Yang, S. \& Fan, L. Synthesis and characterization of sulfonated polyimides bearing sulfonated aromatic pendant group for DMFC applications. Polymer (Guildf) 51, 3887-3898 (2010).
18 Pana, H., Zhua, X. \& Jian, X. Synthesis and properties of sulfonated copoly (phthalazinone ether imides) as electrolyte membranes in fuel cells. Electrochim. Acta 55, 709-714 (2010).

19 Li, Y., Jin, R., Cui, Z., Wang, Z., Xing, W., Qiu, X., Ji, X. \& Gao, L. Synthesis and characterization of novel sulfonated polyimides from 1,4-bis(4-aminophenoxy)naphthyl-2,7-disulfonic acid. Polymer (Guildf) 48, 2280-2287 (2007).

20 Fang, J., Guo, X., Xu, H. \& Okamoto, K.-I. Sulfonated polyimides: Synthesis, proton conductivity and water stability. J. Power Sources 159, 4-11 (2006).

21 Tsuchida, E., Yamamoto, K. \& Shouji, E. Synthetic route to poly(sulfonyl-1,4 phenylenethio- 1,4-phenylene) via a poly(sulfonium cation). Macromolecules 26, 7389-7390 (1993)

22 Tsuchida, E., Yamamoto, K., Jikei, M., Shouji, E. \& Nishide, H. Synthesis of polyphenylene thioethers through cationic oxidative polymerization. J. Macromol. Sci. Chem. A28, 1285-1298 (1991).

23 Shouji, E., Yamamoto, K. \& Tsuchida, E. Synthesis of poly(arylene sulfide) via poly(sulfonium cation) through electrophilic substitution reaction of methyl phenyl sulfide with antimony pentachloride. Chem. Lett. 1927-1930 (1993).

24 Tsuchida, E., Shouji, E. \& Yamamoto, K. Synthesis of high-molecular-weight poly(phenylene sulfide) by oxidative polymerization via poly(sulfonium cation) from methyl phenyl sulfoxide. Macromolecules 26, 7144-7148 (1993).

25 Tsuchida, E., Yamamoto, K., Shouji, E., Katoh, J., Matsuo, M. \& Kamiya, H. Synthesis of block copolymers containing perfluoroalkane and tetrafluoroethyleneperfluoro(propyl vinyl ether) block copolymer with sulfide bonds. Macromolecules 27. 7504-7510 (1994).

26 Yamamoto, K., Shouji, E., Suzuki, F., Kobayashi, S. \& Tsuchida, E. Synthesis of poly(sulfonium cation) by oxidative polymerization of aryl alkyl sulfides. J. Org. Chem. 60, 452-453 (1995).

27 Fang, J., Guo, X., Harada, S., Watari, T., Tanaka, K., Kita, H. \& Okamoto, K. Novel sulfonated polyimides as polyelectrolytes for fuel cell application. 1. synthesis, proton conductivity, and water stability of polyimides from $4,4 c$-diaminodipheny ether-2,2 ф -disulfonic acid. Macromolecules 35, 9022-9028 (2002).

Supplementary Information accompanies the paper on Polymer Journal website (http://www.nature.com/pj) 